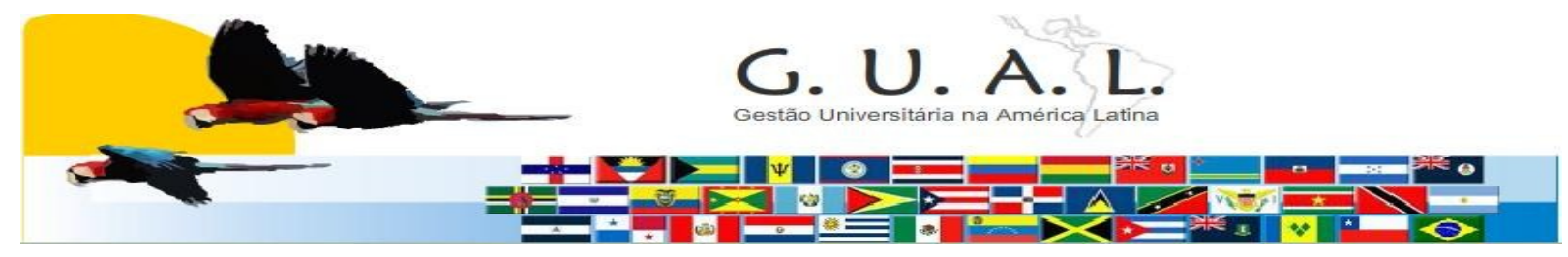

ISSN 1983-4535

\title{
ESTUDO DE VIABILIDADE DE IMPLANTAÇÃO DE UM SISTEMA DE GESTÃO DA QUALIDADE CONFORME REQUISITOS DA ISO 9001:2008 NO CENTRO DE CIÊNCIAS AGRÁRIAS DA UFSC
}

\section{FEASIBILITY STUDY FOR ESTABLISHMENT OF A QUALITY MANAGEMENT SYSTEMREQUIREMENTS AS OF ISO 9001:2008 IN THE CENTRO DE CIÊNCIAS AGRÁRIAS AT UFSC}

Ana Elizabeth Martens, Especialista Universidade Federal de Santa Catarina anamartens@hotmail.com

Recebido em 03/outubro/2011

Aprovado em 28/fevereiro/2012

Sistema de Avaliação: Double Blind Review

Esta obra está sob uma Licença Creative Commons Atribuição-Uso. 


\title{
RESUMO
}

Qualidade na administração é caracterizada como ferramenta essencial para o desenvolvimento de uma gestão eficiente. Cada vez mais os administradores das instituições públicas estão complementando seu planejamento estratégico com metas de qualidade. Esta pesquisa tratou do desenvolvimento de um estudo da viabilidade de implantação de um Sistema de Gestão da Qualidade através da certificação ISO 9001:2008 no Centro de Ciências Agrárias - CCA, da Universidade Federal de Santa Catarina - UFSC. Seu objetivo foi proporcionar à instituição um diagnóstico de qualidade, a fim de que no futuro seja possível agregar os aspectos iniciais da qualidade preparando-se para a certificação. Os dados primários foram adquiridos através do método observativo auxiliado por um roteiro semi estruturado, bem como consultas em manuais e documentos internos da instituição. Os dados secundários foram obtidos por meio de pesquisa bibliográfica a fim de fundamentar a investigação. Com esta pesquisa pode-se aferir que é viável a implantação um Sistema de Gestão da Qualidade no CCA/UFSC desde que se utilize num primeiro momento algumas ferramentas da qualidade, proporcionando desta maneira inúmeros benefícios à unidade de ensino com a adoção deste sistema.

Palavras-chave: ISO 9001:2008. Qualidade. Sistema. Gestão de processos.

\begin{abstract}
Quality management is characterized as an essential tool for the development of an efficient management. Increasingly, managers of public institutions are complementing their strategic planning with quality goals. This research addressed the development of a feasibility study to implement a Quality Management System ISO 9001:2008 certification through the Centro de Ciências Agrárias - CCA, Universidade Federal de Santa Catarina - UFSC. His goal was to provide a diagnosis to the institution of quality, so that in future it is possible to aggregate the initial aspects of quality preparation for certification. The primary data were acquired through observational method aided by a semi-structured, and has consulted manuals and internal documents of the institution. Secondary data were obtained by means of literature to support the research. With this study we can infer that it is feasible to deploy a Quality Management System in the CCA/UFSC since it is used at first some tools of quality, thus providing numerous benefits to the teaching unit with the adoption of this system.
\end{abstract}

Keywords: ISO 9001:2008. Quality. System. Management processes. 


\section{INTRODUÇÃO}

Gestão da qualidade é uma temática que, no decorrer de sua história, passou por inúmeras mudanças acompanhando a evolução das práticas de gestão percorrendo quatro estágios bem definidos: a inspeção do produto, o controle do processo, os sistemas de garantia da qualidade e por fim a gestão da qualidade total. (CARPINETTI, MIGUEL e GEROLAMO, 2007).

Os conceitos de TQM (Qualidade Total) e de Sistemas de Gestão da Qualidade baseados nos requisitos da ISO 9001:2008 estão relacionados ao objetivo de proporcionar atendimento integral ao cliente em relação a um produto ou serviço satisfazendo por completo tal necessidade. Além disso, têm a função de possibilitar às organizações a criação de estratégias para ganhar ou aumentar sua competitividade no mercado.

É fato que as empresas em geral, públicas ou privadas, demonstram uma preocupação constante em aprimorar a gestão de suas atividades. Em particular e por tratar-se do objeto deste estudo, as instituições públicas de ensino superior requisitam como objetivo aumentar a eficiência de seus processos, bem como investir na profissionalização e capacitação de seu quadro de pessoal.

No que tange aos serviços públicos, é responsabilidade do Estado determinar através de critérios específicos quais os serviços que deverão ser públicos ou de utilidade pública e ainda se os mesmos serão prestados diretamente pela estrutura oficial ou delegados a terceiros. Em decorrência desta decisão é que são estabelecidas metas de qualidade podendo ser consideradas ferramentas que impulsionam os processos e as atividades.

Diante do exposto e da necessidade atual de ajuste administrativo o governo federal emitiu uma norma sobre o tema eficiência, assunto que se relaciona diretamente com a administração da qualidade. Trata-se do Decreto n 3.507 de junho de 2000 que cita, "Dispõe sobre o estabelecimento de padrões de qualidade do atendimento prestado aos cidadãos pelos órgãos e pelas entidades da Administração Pública Federal direta, indireta e fundacional, e dá outras providências".

Nesta ótica percebe-se que o Centro de Ciências Agrárias da Universidade Federal de Santa Catarina - objeto de estudo - pode adequar seus processos de gestão de serviços e de atendimento a um padrão de qualidade superior, que poderá resultar num diferencial competitivo para a instituição pública em estudo. 
Destarte, o Estudo de Viabilidade de Implantação do Sistema de Gestão da Qualidade baseado nos Requisitos da ISO 9001:2008 poderá proporcionar inúmeros benefícios ao CCA/UFSC, pois será possível entender suas atividades acadêmicas e administrativas como um todo, além de ser referência caso a instituição decida iniciar a efetiva implantação do sistema.

\section{MARCO REFERENCIAL TEÓRICO}

A gestão da qualidade total e os sistemas de gestão da qualidade são temas recorrentes na administração das empresas, atualmente, nas instituições públicas, também estão sendo utilizados como ferramentas de auxílio à resolução de inúmeros problemas administrativos.

Segundo Tostes (2004, p.94) administração pública pode ser considerada, “Conjunto de órgãos instituídos para a consecução dos objetivos do Governo; em sentido material, é o conjunto das funções necessárias aos serviços públicos em geral; em acepção operacional é o desempenho perene e sistemático, legal e técnico, dos serviços próprios do estado ou por ele assumidos em benefício da coletividade".

A administração em geral possui várias atividades e princípios a saber que a identificam como planejar, dirigir, comandar e coordenar. Na administração pública também se utiliza estes princípios, além de estudá-la no sentido amplo e no sentido estrito (SANTOS, 2003).

Em relação aos diferentes institutos da administração pública a se estudar ainda disserta Santos (2003, p.127), “A administração pública pode ser observada sob duas perspectivas. No sentido amplo engloba os órgãos governamentais e administrativos. No sentido estrito compreende as pessoas jurídicas, órgãos e agentes públicos que exercem a função administrativa e a atividade administrativa exercida por aqueles entes."

Destaca-se nestes conceitos o caráter social da gestão da coisa pública, pois diferente da administração tradicional a pública visa o bem-estar social e o cumprimento das determinações legais do Estado proporcionando a tutela da sociedade e dos cidadãos.

Pimenta (1998) explica que o Estado brasileiro em meados do século XIX, apresentou uma linha de trabalho onde a participação na economia do país foi tradicional. Nas décadas de 40 e 50 o governo inicia um processo de centralização através de um modelo weberiano de burocracia, em contrapartida surge uma administração descentralizada nas décadas de 60 a 80 possibilitando uma flexibilidade maior na contratação de servidores (PIMENTA, 1998).

Na era Vargas conforme Paula (2002) foi desenvolvida pela administração pública uma gestão tecnicista, autoritária e centralizadora afastando-se da sociedade em geral. Foi na 
procura por profissionalização dos administradores e por utilização de ferramentas de auxílio na gestão que a década de 70 foi marcada.

Este período foi muito importante, pois neste momento surge a necessidade de capacitação dos servidores e gestores públicos bem como o aperfeiçoamento dos requisitos de contratação. Estes fatores sinalizaram indícios dos princípios da qualidade.

Nos idos dos anos 80 com as crises econômicas, políticas e sociais as dificuldades foram agravadas pela baixa qualidade dos serviços públicos. Este quadro possibilita a criação de novos modelos e técnicas de administração para o desenvolvimento do setor (SOUZA, 2002).

Diante do exposto percebe-se um expressivo déficit na qualidade dos serviços públicos caracterizando-se como um sério problema na sociedade de vários países. Souza (2002) em sua argumentação, esclarece o quanto é importante para o Estado a profissionalização de seus serviços e a criação e utilização de modelos de gestão baseados principalmente nas empresas do setor privado.

Littman (2006, p. 10) também contribui afirmando, “A indústria privada usa a Gestão da Qualidade Total para competir e sobreviver no mercado. No caso do governo, as razões vão desde oferecer um melhor serviço ao público, diminuir gastos do orçamento, conseguir e manter melhores funcionários, até mesmo... sobreviver, também!"”.

Nesta linha pode-se dizer que as ferramentas da qualidade apresentam-se como um recurso eficiente a fim de contribuir com melhorias na gestão pública. O autor Sanders (2005, p.77) define para este estudo, “O conceito de qualidade existe há muitos anos, embora seu significado tenha se modificado e evoluído com o passar do tempo. No início do século XX, gestão da qualidade significava inspecionar os produtos para assegurar que eles atendiam às especificações".

Conforme Carpinetti, Miguel e Gerolamo (2007) o sistema da qualidade que é aplicado através da ISO tem o objetivo de atingir empresas interessadas em aplicar um sistema de gestão da qualidade, isto se dá, entre outros fatores, pela exigência do mercado.

É desejável que as empresas, quando buscam aplicar a ISO da qualidade contemplem todas as exigências da norma aplicáveis a seus produtos e serviços, abrangendo o escopo de seu sistema de gestão da qualidade (MELLO, 2002).

Em se tratando de qualidade vale ressaltar também os conceitos da TQM, ou qualidade total. A TQM está ligada ao sistema de gestão da qualidade, assim Kiser e Sashkin (1993, p.34) esclarecem: “TQM significa que a cultura da organização é definida pela busca 
constante da satisfação do cliente através de um sistema integrado de ferramentas, técnicas e treinamento. Isso envolve a melhoria contínua dos processos organizacionais, resultando em produtos e serviços de alta qualidade".

Em conformidade com os requisitos da ISO 9001:2008 o sistema de gestão da qualidade é composto por cinco requisitos a saber: sistema de qualidade, responsabilidade da direção, gestão de recursos, realização do produto e medição, análise e melhoria. (CARPINETTI, MIGUEL e GEROLAMO, 2007).

Afere-se assim a partir dos autores citados que a eficácia do sistema de gestão da qualidade depende muito da aplicação efetiva dos princípios da qualidade. Estes princípios são: Foco no cliente, liderança, envolvimento das pessoas, abordagem por processos, visão sistêmica, melhoria contínua, decisão embasada em fatos e relação de benefício mútuo.

\section{METODOLOGIA}

Com o objetivo de estudar a viabilidade de implantação de um sistema de gestão da qualidade conforme requisitos da ISO 9001:2008 no CCA/ UFSC a pesquisa caracterizou-se como descritiva de caráter qualitativo.

Richardson (1999, p. 80) explica “os estudos que empregam uma metodologia qualitativa podem descrever a complexidade de determinado problema, analisar a interação de certas variáveis, compreender e classificar processos dinâmicos vividos por grupos sociais".

Para construir uma pesquisa descritiva e propor uma solução para o problema escolhido a ser estudado, foi preciso construir uma base teórica e consistente que se mostrou de grande importância para o desenvolvimento do assunto. Desta forma, realizou-se inicialmente um levantamento bibliográfico.

Foi utilizada a ferramenta estudo de caso como modelo, Lima (2004, p.31) explica sobre sua utilização "[...] corresponde a uma das formas de realizar uma pesquisa empírica de caráter qualitativo sobre um fenômeno em curso e em seu contexto real.”.

Este método se enquadrou perfeitamente nesta proposta de pesquisa por ter possibilitado o estudo aprofundado da individualidade dos procedimentos administrativos, bem como seus reflexos no coletivo da instituição. Além disso, auxiliou o desenvolvimento da proposta de um sistema de gestão da qualidade que contribuirá para a efetivação das atividades desenvolvidas.

Em virtude do reduzido tempo para desenvolvimento da pesquisa foi decidido trabalhar com uma amostra escolhida aleatoriamente, ou seja, um dos centros de ensino da UFSC. 
No que se refere a coleta de dados da pesquisa foi utilizado o método de observação do cotidiano das atividades administrativas do CCA/UFSC através de um roteiro de diagnóstico de gestão da qualidade desenvolvido pela pesquisadora.

A coleta de dados primários realizou-se através do método de observação das atividades administrativas realizadas no cotidiano da organização, bem como na experiência da pesquisadora que atua diretamente na execução e controle de atividades acadêmicas da instituição.

O método citado pode ser definido, "Método em que o observador participa da vida diária das pessoas em estudo, tanto abertamente no papel de pesquisador, como assumindo papéis disfarçados, observando fatos que acontecem, escutando o que é dito e questionando as pessoas ao longo de um período de tempo." (BECKER \& GEER APUD TRAUTH \& O'CONNOR, 2000). Este método foi escolhido devido à facilidade na obtenção de informações para a pesquisa além daquelas encontradas nos documentos e manuais.

Os dados secundários foram adquiridos por meio de pesquisa bibliográfica de livros, além da busca de informações institucionais da UFSC - Universidade Federal de Santa Catarina; como documentos oficiais, manuais, legislações entre outros.

Mattar (1996) descreve, "Dados secundários são dados colhidos para uma finalidade diferente daquela do problema em pauta. Os dados primários, por outro lado, são coletados ou produzidos pelo pesquisador com a finalidade específica de resolver o problema de pesquisa".

Para a perfeita análise dos dados coletados na pesquisa Mattar (1995) explica que para não comprometer a qualidade, precisão e confiabilidade dos resultados obtidos é necessário escolher a correta técnica de análise.

Em virtude do citado, a análise de dados deste trabalho foi processada de acordo com os resultados obtidos na observação das atividades administrativas. Ao analisar estas informações comparando-a aos autores da área desenvolveu-se a proposta de um Sistema de Gestão da Qualidade conforme os princípios e requisitos da ISO 9001:2008, objetivo deste estudo.

\section{DESCRIÇÃO DA REALIDADE DE ESTUDO}

Para esta pesquisa foi realizada uma análise da realidade administrativa do Centro de Ciências Agrárias da UFSC, através do método de observação. Com o intuito de obter maior 
simplicidade e clareza nos processos deste estudo de viabilidade foi utilizada a metodologia de CARPINETTI, MIGUEL e GEROLAMO (2007, p.31).

Os autores sugerem que inicialmente seja realizada uma Avaliação Pré-Implantação, seguida pela Implementação do Sistema de Gestão da Qualidade com as quatro etapas: I Levantamento de Necessidades, II - Projeto do Sistema, III - Implantação e IV - Auditoria de Certificação e foi esta a metodologia conduziu esta investigação.

A Avaliação de Pré-Implantação foi realizada no Centro de Ciências Agrárias da UFSC através do Roteiro de Diagnóstico da Qualidade sugerido pelos autores CARPINETTI, MIGUEL e GEROLAMO (2007, p.32 e 33). Pode-se observar que a instituição apresenta muitos sinais da qualidade em suas rotinas, porém estas não apresentam padrões formais.

Foi utilizado também o método de observação das rotinas administrativas e acadêmicas que são realizadas nos departamentos do centro de ensino em estudo. Além disso fez-se uma busca em documentos oficiais e manuais que pudessem refletir algum procedimento ou idéia de qualidade, bem como noções de padronização.

Inicialmente observou-se que o CCA não possui um manual formal da qualidade. As tarefas administrativas, ou seja, os processos são regidos por legislações próprias, servindo a lei como um guia de procedimentos no andamento dos mesmos. As regulamentações, no entanto, não citam ritos que assegurem a qualidade dos atos, apenas determinam como eles devem ser instruídos para serem considerados válidos, citando muitas vezes o conteúdo e não a forma.

Quanto aos processos internos da instituição, existem algumas padronizações em relação às atividades acadêmicas com prazos definidos. A cada ano é aprovado através de uma resolução um calendário acadêmico com todos os prazos a serem seguidos pelos departamentos e centros. Em relação as demais rotinas administrativas, fica a cargo de cada unidade escolher a melhor forma de executar e concluir suas tarefas, não existindo assim um padrão de execução na maioria das atividades, apenas algumas orientações isoladas.

$\mathrm{Na}$ área da informação a UFSC disponibiliza inúmeros sistemas internos de gestão. Os departamentos e centros utilizam (em média) sete sistemas que funcionam de maneira individual e parcialmente integrada. O Núcleo de Processamento de Dados - NPD da instituição está trabalhando para uma ação de unificação e integração de todos os sistemas da autarquia com o intuito de criar uma base de dados consistente, proporcionando maior agilidade na confecção das tarefas, fidedignidade das informações, redução da burocracia e do retrabalho, bem como segurança digital. 
No que se refere à Política de Qualidade é possível determinar que funciona de maneira informal. Cada unidade educacional cria ou não as suas próprias políticas que, na maioria das vezes, não são padronizadas e não estão registradas nem formalizadas, são resultantes de hábitos ou rotinas que ao longo do tempo foram repassadas de gestão em gestão.

O quadro de pessoal da UFSC é composto de maneira heterogênea e diferenciada. Os servidores são contratados através de concurso público regidos pela Lei 8.112, de 11 de dezembro de 1990, que trata do Regime Jurídico dos Servidores Públicos Civis da União, das Autarquias e das Fundações Públicas Federais. Desta forma não é possível determinar critérios para contratação, pois todo cidadão têm acesso via concurso público e já existe lei que regulamenta o grau de instrução e experiência para cada cargo.

A infraestrutura da instituição está em geral apropriada. De acordo com as possibilidades orçamentárias vêm atualizando suas unidades tecnológicas, de ensino e estrutura interna de trabalho. Alguns departamentos e centros mais antigos estão aos poucos, sendo reestruturados. Estas mudanças demandam planejamento e tempo, pois todas as aquisições e serviços devem ser realizadas de acordo com a Lei 8.666, de 21 de junho de 1993 que institui normas para licitações e contratos da administração pública.

É possível afirmar que o instrumento mais próximo de integrar um sistema de gestão da qualidade na UFSC seja a Ouvidoria. O Conselho Universitário aprovou sua criação em 28 de maio de 1996. O principal argumento foi a efetiva transparência administrativa, com base em um movimento participativo com condições de vivenciar, opinar, criticar, informar, sugerir ou elogiar aquilo que se tem o direito de compartilhar. ${ }^{1}$

Carpinetti, Miguel e Gerolamo (2007) sugerem a identificação dos requisitos dos clientes, ou seja, parte-se dos produtos ou serviços da empresa identificando os requisitos qualificadores (sem os quais a empresa não atende minimamente aos requisitos dos clientes) e os requisitos ganhadores de pedidos (que são os requisitos que fazem a diferença).

Para determinar com maior precisão quais são os requisitos qualificadores e os requisitos ganhadores de pedidos seria necessário um trabalho de levantamento das atividades e processos da instituição, cujo foco não é objetivo desta pesquisa. Em virtude deste item não compor os objetivos específicos desta pesquisa foi possível através do processo de observação relacionar de maneira superficial alguns requisitos:

1 Disponível em: http://www.ufsc.br Acesso em: 27/08/2009. 


\begin{tabular}{|c|c|}
\hline REQUISITOS QUALIFICADORES & REQUISITOS GANHADORES DE PEDIDOS \\
\hline $\begin{array}{l}\rightarrow \text { Infraestrutura básica; } \\
\rightarrow \text { Corpo docente e técnicos administrativos; } \\
\rightarrow \text { Corpo discente; }\end{array}$ & $\begin{array}{l}\rightarrow \text { Atendimento rápido e eficaz pelo setor } \\
\text { administrativo; } \\
\rightarrow \text { Redução da burocracia nos processos; } \\
\rightarrow \text { Infraestrutura inovadora; } \\
\rightarrow \text { Informatização de todos os processos; } \\
\rightarrow \text { Formação técnica de especializada; }\end{array}$ \\
\hline
\end{tabular}

QUADRO 1 Requisitos qualificadores e ganhadores de pedidos

Fonte: Adaptado de CARPINETTI, MIGUEL e GEROLAMO (2007, p.103).

Outro subitem do levantamento de atividades é a identificação das atividades críticas. Para mapear as atividades críticas os referidos autores sugerem que se realize o mapeamento dos processos primários e de suporte da organização. O mapeamento da estrutura funcional foi possível realizar, pois já existe na estrutura administrativa do centro um organograma funcional oficial.

Enfim, faz-se preciso determinar os processos e as atividades críticas que sejam relacionados com a qualidade e de quem serão estas responsabilidade, ou seja, a criação de uma matriz que relacione quais são os requisitos de clientes e as atividades realizadas pela empresa. Dentro do processo de observação pode-se relacionar:

\begin{tabular}{|c|c|}
\hline REQUISITOS DOS CLIENTES & ATIVIDADES REALIZADAS EMPRESA \\
\hline $\begin{array}{l}\rightarrow \text { Excelência no atendimento; } \\
\rightarrow \text { Excelência no ensino; } \\
\rightarrow \text { Infraestrutura básica adequada ao ensino; } \\
\rightarrow \text { Corpo docente capacitado; } \\
\rightarrow \text { Auxílios financeiros, bolsas, moradia, } \\
\text { alimentação; } \\
\rightarrow \text { Ampliação do acesso às vagas e aos cursos } \\
\text { novos; }\end{array}$ & $\begin{array}{l}\rightarrow \text { Atividades típicas de ensino, pesquisa e } \\
\text { extensão; } \\
\rightarrow \text { Laboratórios especializados; } \\
\rightarrow \text { Utilização de tecnologias; }\end{array}$ \\
\hline
\end{tabular}

QUADRO 2 Requisitos dos clientes e atividades realizadas pela empresa.

Fonte: Adaptado de CARPINETTI, MIGUEL e GEROLAMO (2007).

A partir das observações realizadas no planejamento estratégico e nas atividades da instituição foi possível propor as políticas e os objetivos da qualidade.

\subsection{Modelo proposto - Sistema de Gestão da Qualidade}

O presente artigo teve como objetivo apresentar os resultados de uma investigação realizada acerca da viabilidade de implantação de um Sistema de Gestão da Qualidade conforme requisitos da ISO 9001:2008.

De acordo com os requisitos da ISO 9001:2008 e a partir dos estudos de viabilidade aferidos nesta pesquisa foi possível sugerir um modelo de sistema de gestão da qualidade 
conforme os autores CARPINETTI, MIGUEL e GEROLAMO (2007, p.97) para o CCA/UFSC. A verificação de tal fato, de certa forma, não surpreende, em virtude da presença de inúmeros requisitos informais de qualidade, o que leva a crer que a viabilidade de implantação do mesmo é possível.

\subsection{Centro de Ciências Agrárias da Universidade Federal de Santa Catarina}

O CCA/UFSC é um centro de ensino que iniciou suas atividades em 1975. Está localizado na Rodovia Admar Gonzaga, 1346 no Bairro de Itacorubi em Florianópolis - SC. É composto por cinco departamentos de ensino, o Departamento de Aquicultura, de Ciência e Tecnologia de Alimentos, de Engenharia Rural, de Fitotecnia e de Zootecnia e Desenvolvimento Rural.

Além disso, possui setores de Pós-Graduações, Laboratórios Especializados e Fazendas e Bases Experimentais de estudo. Estas instalações auxiliam as atividades de pesquisa e extensão, bem como têm a função de oferecer disciplinas aos cursos de graduação e pósgraduação, além de atender à comunidade em geral.

\subsection{Política de qualidade}

Foram identificados como objetivos da qualidade: Capacitação docente e técnicoadministrativa; Redução de custos e retrabalho; Melhoria no atendimento ao aluno, ao servidor e à comunidade e Ensino de excelência.

Sugeriu-se, assim como política da qualidade: “É Política de Qualidade do CCA/UFSC proporcionar a excelência no ensino, pesquisa e extensão, nos processos, no atendimento aos alunos, servidores e comunidade de forma sustentável, servindo o bem comum".

\subsection{Sistema documental}

O sistema documental da instituição poderá ser composto pelo manual da qualidade com os devidos registros e procedimentos das atividades e tarefas, além disso, também poderá fazer parte deste sistema as leis, resoluções, normas, calendário oficial e demais determinações que a gestão decidir por documentar.

A fim de exemplificação deverá apresentar as instruções de cada tarefa, os responsáveis por cada decisão e o tipo de análise a se realizar para efetuar as devidas ações corretivas ou de prevenção. Estas atividades, bem como os critérios de revisão, edição, validação e registro do sistema de documentos deverão atender os requisitos propostos pela ISO 9001:2008. 


\subsection{Responsabilidade da direção}

Este requisito poderá ser atendido com a instituição designando como coordenadores de qualidade os chefes de serviço de expediente de cada departamento, bem como com a participação de outros servidores que demonstrem interesse em contribuir com o tema.

Para a formação do conselho da qualidade no CCA/UFSC sugere-se a participação dos chefes de serviço de expediente, do coordenador administrativo do centro e de professores designados pelo diretor da unidade também envolvidos com a questão da qualidade na instituição.

\subsection{Gestão de recursos}

Analisando os requisitos necessários para a certificação a instituição precisará adequarse em relação a alguns pontos considerados críticos. Um tópico de grande importância é o tópico: "Foco no Cliente", fazendo-se necessária uma completa capacitação dos servidores que atuam na linha de frente (atendimento).

Em virtude de inúmeras nomeações a instituição recepcionou vários servidores. É necessário que estes novos servidores conheçam os procedimentos administrativos e acadêmicos a fim de cumprir suas funções adequadamente. Por este motivo, sugere-se a criação e aplicação de um programa de capacitação para os novos servidores que vislumbre uma ambientação das rotinas e dos ambientes onde os mesmos serão inseridos.

Percebe-se assim, que o item capacitação/treinamento é fator determinante para o sucesso do sistema. O planejamento de programas de treinamento baseados na temática da qualidade e nos tópicos que a instituição considera relevantes para o sistema irá resultar em atividades mais consistentes e eficazes.

Quanto à gestão de recursos de infraestrutura a instituição precisará adequar a estrutura atual para atender seus requisitos ganhadores de pedido com maior eficácia além de manter esta estrutura efetuando manutenções corretivas e de prevenção.

\subsection{Realização do produto/serviços}

A prestação de serviços no CCA/UFSC abrange a divulgação do conhecimento, bem como a formação de profissionais. Nesta instituição o ensino, a pesquisa e a extensão possuem valor social significativo, além do compromisso de formar profissionais capacitados e aptos a exercerem as funções disponíveis no mercado de trabalho. 
Deste modo o referido sistema deverá estabelecer os seguintes procedimentos para o sucesso neste ambiente, bem como proporcionar o suporte necessário para o desenvolvimento das atividades.

\subsubsection{Suporte administrativo}

Pode-se também incluir fatores como a infraestrutura e o ambiente de trabalho, estes itens são considerados críticos por caracterizarem o escopo da execução do mesmo. As pessoas são os principais condutores de um sistema de qualidade, desta forma é necessário ressaltar que o papel de participação dos servidores é peça fundamental deste sistema.

Sugere-se, portanto, um trabalho de motivação e incentivo, demonstrando as vantagens de atividades menos burocráticas, com menor índice de erros positivando os resultados obtidos.

\subsubsection{Ações preliminares da qualidade}

A ferramenta $5 \mathrm{~S}$ é uma sugestão de ação da qualidade que aplicada de maneira comprometida será bastante útil porque irá preparar os servidores e a instituição como um todo para o processo de implantação do sistema de gestão da qualidade.

\subsubsection{Direção participativa}

O planejamento é a etapa mais importante da empresa, sem ele não há direção a seguir, além de não deixar claro aos colaboradores quais as metas que deverão alcançar. Desta forma, planejar e incluir no planejamento estratégico as ações de qualidade faz-se imprescindível para um eficiente sistema de gestão.

\subsubsection{Comunicação e divulgação da qualidade}

Para que uma organização logre êxito em seus processos ela precisa estar atenta à comunicação com seus colaboradores. A comunicação interna é fator relevante na cadeia da qualidade, pois quanto mais informados de suas ações os servidores estiverem, maior será a participação dos mesmos no processo de mudança organizacional.

\subsubsection{Medição, análise e melhoria}

Com a função de atender ao requisito do sistema da qualidade medição, análise e melhoria a instituição deverá estar atenta aos seguintes tópicos: pesquisa para medir a 
satisfação dos alunos, servidores e comunidade, execução de auditorias internas organizadas e realizadas pelo conselho da qualidade, além da implantação das reuniões da qualidade.

Sugeriu-se também a adoção de indicadores de monitoramento. No quadro a seguir relacionam-se alguns indicadores e seus respectivos objetivos.

\begin{tabular}{|l|l|}
\hline \multicolumn{1}{|c|}{ INDICADORES } & \multicolumn{1}{c|}{ OBJETIVO } \\
\hline Reclamações na ouvidoria da UFSC & Qualidade \\
\hline Evasão escolar nas ciências agrárias & Excelência no Ensino \\
\hline Assiduidade dos servidores & Qualidade \\
\hline Ocorrência de não conformidades & Qualidade \\
\hline Empregabilidade dos alunos egressos & Excelência no Ensino \\
\hline Cerificações ambientais & Sustentabilidade \\
\hline Projetos ambientais & Sustentabilidade \\
\hline
\end{tabular}

QUADRO 3 Indicadores utilizados na empresa

Fonte: Adaptado de CARPINETTI, MIGUEL e GEROLAMO (2007, p.103).

\section{CONSIDERAÇÕES FINAIS}

Estudar a praticabilidade de um Sistema de Gestão da Qualidade numa instituição pública caracterizou-se como um desafio no que tange à sua adequação. Apresentou também significativa contribuição no que se refere à investigação dos vários aspectos da gestão pública educacional relacionados à gestão da qualidade.

Itens como infraestrutura deficitária, excesso de burocracia, demora na condução e resolução dos processos, falta de informações no atendimento aos alunos e à comunidade, além de retrabalho e sobrecarga de atividades devido à ausência de reposição de servidores, demonstram um pouco da realidade observada na instituição pesquisada, bem como em outras universidades públicas do país.

Considerando este contexto a experiência de realizar uma pesquisa no CCA/UFSC proporcionou o conhecimento mais aprofundado da organização e de seus procedimentos. Foi possível também vislumbrar possibilidades de profissionalização através das ferramentas da qualidade, bem como de várias áreas para estudos futuros.

Percebe-se também que a UFSC e seus departamentos possuem uma variedade de profissionais atuando em diferentes áreas, fazendo crer que esta complexidade pode auxiliar na resolução dos problemas enfrentados diariamente. Contudo, a instituição necessita de uma gestão capaz de dispor destas diferenças de forma produtiva.

Através destas análises foi possível identificar que a implantação da gestão da qualidade no CCA/UFSC é possível, todavia, é preciso que sejam tomadas várias decisões antes da 
aplicação efetiva do sistema para que os requisitos da ISO 9001:2008 sejam preenchidos adequadamente.

Já a sensibilização e o treinamento dos servidores mostrou-se ponto essencial para o desenvolvimento eficiente do referido sistema. Assim, é preciso que antes de iniciar este programa se planeje uma ação mais efetiva em relação à força de trabalho. Verificou-se, também que a unidade de ensino possui grande interesse em efetivar este requisito.

Infraestrutura e recursos tecnológicos são outro destaque de igual importância. Estes precisam ser adequados para que seja possível a melhor execução da atividade fim. No CCA/UFSC, bem como em outros centros, esta questão não depende somente da unidade de ensino, pois a divisão dos recursos é realizada pela administração central, sendo necessário, portanto, constante planejamento de aquisições e atualizações que a sua conclusão seja efetivada.

$\mathrm{O}$ interesse e a determinação da direção em implantar um sistema que facilite a consecução das atividades e proporcione maior credibilidade e transparência à instituição é um requisito relevante na coordenação do processo. Na instituição pesquisada é verificada disposição em apoiar este processo.

Em relação às limitações e dificuldades cita-se a questão orçamentário-financeira. Todos os gastos na iniciativa pública deverão ser realizados de acordo com a legislação em vigor, assim para dispor o pagamento a uma instituição certificadora será necessária a abertura de um processo licitatório o qual deverá ser planejado com antecedência para o próximo exercício.

No âmbito dos recursos humanos foi observado que é uma limitação o fato de possuir um quadro de servidores reduzido em relação à quantidade e complexidade de tarefas. Esta redução ocasiona sobrecarga de trabalho, diminuindo a motivação dos servidores, bem como a vontade em cooperar no planejamento e execução de novos projetos.

Destarte, esta pesquisa leva a crer que é viável a implantação de um Sistema de Gestão da Qualidade desde que atendidas as considerações citadas, bem como seja desenvolvido um detalhado planejamento para o projeto.

\section{REFERÊNCIAS}

CARPINETTI, Luiz C. R; MIGUEL, Paulo Augusto C. Miguel; GEROLAMO Mateus, Cecílio. Gestão da Qualidade ISO 9001:2000: princípios e requisitos. São Paulo: Atlas, 2007. 
KISER, Kenneth J.; MARSHALL, Sashkin. Gestão da qualidade total na prática. $1^{\circ} \mathrm{Ed}$. Rio de Janeiro: Editora Campus, 1994.

LIMA, Manolita C. Monografia: a engenharia da produção acadêmica. São Paulo: Editora Saraiva, 2004.

LITTAN, Ian D.; CARR, K. David. Excelência nos serviços públicos. $1^{\circ}$ Ed. Rio de Janeiro: Qualitymark, 1996.

LODI, J. B. História da Administração $1^{\circ}$ ed. São Paulo: Editora Thomson 2003.

MATTAR, Fauze Najib; Pesquisa de marketing: metodologia e planejamento $-1.5^{\circ}$ ed. São Paulo: Atlas, 1999.

MALHOTRA, Naresh K; Pesquisa de marketing: uma orientação aplicada. $3^{\circ}$ ed. Porto Alegre: Bookman, 2001.

MALHOTRA, Naresh K; Pesquisa de marketing: uma orientação aplicada. $4^{\circ}$ ed. São Paulo: Bookman, 2006.

MELlO, P. H. C.; SILVA, C. E. S. da; TURRIORI, J. B.; SOUZA, L. G. M. de. ISO 9001:2000. 1 ed. São Paulo: Editora Atlas S/A, 2002.

MORAES, Alexandre de. Reforma Administrativa: Emenda Constitucional $\mathbf{n}^{\circ}$ 19/98. Ed.3. São Paulo: Atlas, 1999.

RICHARDSON, R. J. Pesquisa social: métodos e técnicas. 3. Ed. São Paulo: Atlas, 1999.

SANTOS, Alvacir. C. Princípio da eficiência da administração pública. 1 ed. São Paulo: LTR Editora Ltda, 2003.

TRAUTH, Eileen M. \& O'CONNOR, Barbara. A study of the interaction between information technology and society: an illustration of combined qualitative research methods. [online], 2000. [http://www.cba.neu.edu/ etrauth/works/ifip5.txt].

UFSC. Histórico. Disponível em: < http://www.ufsc.br/paginas/historico.php > Acesso em 28 de março de 2009.

SANDERS, Nada R.; REID, R. Dan. Gestão de Operações. Ed. 1.Rio de Janeiro: Editora LTC, 2005. 